\title{
Determination of Benzalkonium Chloride in Ophthalmic Solutions by Stability-Indicating HPLC Method: Application to a Stability Study
}

\author{
Hashem AlAani ${ }^{1 *}$, Yasmin AlNukkary ${ }^{2}$ \\ ${ }^{1}$ Department of Chemistry, Faculty of Science, Damascus University, Damascus, Syria. ${ }^{2}$ Department of Pharmaceutical Chemistry and Drug Quality \\ Control, Faculty of Pharmacy, Damascus University, Damascus, Syria.
}

\begin{tabular}{l} 
ARTICLE INFO \\
\hline Article history: \\
Received on: 29/02/2016 \\
Revised on: $15 / 03 / 2016$ \\
Accepted on: 06/04/2016 \\
Available online: $28 / 05 / 2016$ \\
\hline Key words: \\
Benzalkonium chloride, \\
Ophthalmic solutions, HPLC, \\
Stability-indicating, In-use \\
stability. \\
\hline
\end{tabular}

\section{INTRODUCTION}

Ophthalmic preparations are sterile aqueous or oily solutions or suspensions of one or more active materials. These products are normally packed in suitable multi-dose containers that allow the instillation of successive drops of the preparation (Semwal et al., 2014). Microbial contamination or proliferation during storage and use of ophthalmic preparations may lead to product spoilage or may cause serious ocular infections (Semwal et al., 2014; BP, 2013). Protection of these multi-dose products is usually achieved by using of suitable preservatives (Semwal et al., 2014). Benzalkonium chloride (BAC), a mixture of alkylbenzyldimethylammonium chlorides [Fig. 1] (USP, 2012), is the most commonly preservative used in various dosage forms including ophthalmic preparations (Liu et al., 2009). It was first used in the 1940s; and since then, BAC has been used in nearly all classes of ophthalmic solutions, from antiglaucoma products

* Corresponding Author

Hashem AlAani, Department of Chemistry, Faculty of Science,

Damascus University, Damascus, Syria.Email:hashim.ani85@gmail.com to OTC artificial tear solutions (Freeman and Kahook, 2009). The general concentrations range of BAC used in pharmaceutical preparations is $0.002 \%-0.02 \%$, but it could be up to $0.2 \%$ in some cases, depending on different factors in ophthalmic formulations (Liu et al., 2009).

In-use stability is a stability study applied for multi-dose products to ensure that the product preserves its quality parameters after opening during use period. The physical, chemical and microbial properties of the product susceptible to change during storage should be determined over the period of the proposed inuse shelf-life; and for liquids, preservatives, per content and effectiveness, need to be evaluated in this study (WHO, 2009).

A number of analytical methods have been reported for the estimation of BAC in various products including ophthalmic preparations (Agarwal et al., 2013; Al-Fakhory et al., 2014; Chiapetta et al., 2011; Dudkiewicz-Wilczyńska et al., 2004; Gaber et al., 2012; Jovovic' et al., 2012; Kapakayala et al., 2013; Kostić et al., 2012; Mehta et al., 2010; Rao et al., 2013; Santos et al., 2010; Shaikh and Patil, 2013; Shen et al., 2009; Trivedi and Patel, 2010; Trivedi et al., 2013). However, the described methods were 
limited to a number of ophthalmic preparations, and some of them determined the BAC as total not as homologs. Therefore, the aim of this work was to develop a simple stability-indicating HPLC method to determine BAC as homologs, and to prove its applicability in common ophthalmic solutions that contain one or more of the following active ingredients: Brimonidine tartrate, Chloramphenicol, Dexamethasone sodium phosphate, Dorzolamide hydrochloride, Ketorolac tromethamine, Latanoprost, Naphazoline hydrochloride, Olopatadine hydrochloride, Pheniramine maleate, Timolol maleate, and Tetrahydrozoline hydrochloride.

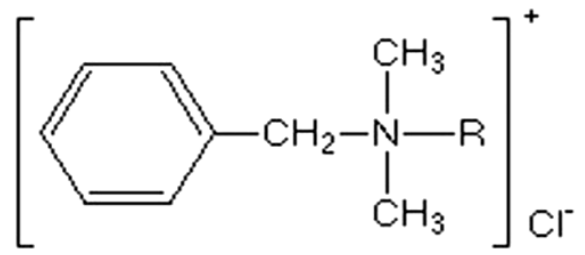

Fig. 1: Chemical structure of Benzalkonium chloride (BAC) in which $R$ represents a mixture of alkyls, including all or some of the group beginning with n-C8H17 and extending through higher homologs, with n-C12H25, n$\mathrm{C} 14 \mathrm{H} 29$, and $\mathrm{n}-\mathrm{C} 16 \mathrm{H} 33$ composing the major portion

As application of the proposed method, it was used for BAC estimation in various marketed ophthalmic solutions and during in-use stability study.

\section{MATERIALS AND METHODS}

\section{Chemicals and solutions}

Benzalkonium chloride for system suitability reference standard was purchased from European Pharmacopoeia (EDQM), Batch No. 3.0. Benzalkonium chloride reference standard was purchased from U.S. Pharmacopoeia, Lot L1I130. Benzalkonium chloride $50 \%$ solution was purchased from Merck, Germany. All ophthalmic solutions, active ingredients, and excipients were kindly supplied by DIAMOND PHARMA, Syria. Acetonitrile used was of HPLC grade. All other reagents used were of analytical grade.

\section{Chromatographic conditions}

Analysis was performed with a HPLC (LaChrom ELITE, VWR-Hitachi, Germany, equipped with L-2130 pump, L-2200 auto sampler, L-2300 column oven, and UV photo diode array detector L-2455). The out-put signal was monitored and processed using EZ Chrom ELITE software.

A Macherey-Nagel Nucleodur 100-5 CN column with dimensions of $250 \mathrm{~mm} \times 4.6 \mathrm{~mm}, 5 \mu \mathrm{m}$ was used. A Thermo CPS Hypersil column with same dimensions was used in robustness study.

The isocratic mobile phase comprised of acetonitrile potassium dihydrogen phosphate buffer $(\mathrm{pH} 5.5 ; 0.05 \mathrm{M})$ (70:30, $\mathrm{v} / \mathrm{v})$. The mobile phase was filtered through $0.45 \mu \mathrm{m}$ membrane filter, degassed in ultrasonic bath and pumped from the respective solvent reservoir to the column at a flow rate of $1 \mathrm{~mL} /$ minute. All analysis was done at $25^{\circ} \mathrm{C}$ and the detection wavelength was 210 $\mathrm{nm}$. The injection volume was $50 \mu \mathrm{L}$.

\section{Method validation}

The proposed HPLC method was validated according to ICH guideline (ICH, 2005), with the aspect of system suitability, specificity, linearity, precision, accuracy, robustness, carryover and filter validation.

\section{Forced degradation studies}

Forced degradation studies were conducted to prove the stability-indicating property of the developed method.

\section{Stock solution}

Benzalkonium chloride stock solution having a concentration of $5 \mathrm{mg} / \mathrm{mL}$ was prepared in mobile phase and spiked with placebo.

\section{Acidic degradation study}

$1 \mathrm{~mL}$ of stock solution was transferred into a $50 \mathrm{~mL}$ volumetric flask containing $20 \mathrm{~mL}$ of mobile phase. $1 \mathrm{~mL}$ of $1 \mathrm{M}$ $\mathrm{HCl}$ was added to the volumetric flask, and then the flask was kept at $70^{\circ} \mathrm{C}$ for about 1 hour in water bath. Then the solution was allowed to attend ambient temperature, neutralized by $1 \mathrm{M} \mathrm{NaOH}$, and the volume was made up to the mark with mobile phase.

\section{Alkaline degradation study}

$1 \mathrm{~mL}$ of stock solution was transferred into a $50 \mathrm{~mL}$ volumetric flask containing $20 \mathrm{~mL}$ of mobile phase. $5 \mathrm{~mL}$ of $1 \mathrm{M}$ $\mathrm{NaOH}$ was added to the volumetric flask, and then the flask was kept at $70^{\circ} \mathrm{C}$ for about 1 hour in water bath. Then the solution was allowed to attend ambient temperature, neutralized by $1 \mathrm{M} \mathrm{HCl}$, and the volume was made up to the mark with mobile phase.

\section{Oxidative degradation study}

$1 \mathrm{~mL}$ of stock solution was transferred into a $50 \mathrm{~mL}$ volumetric flask containing $20 \mathrm{~mL}$ of mobile phase. $1 \mathrm{~mL}$ of $3 \%$ $\mathrm{H}_{2} \mathrm{O}_{2}$ was added to the volumetric flask, and then the flask was kept at $70^{\circ} \mathrm{C}$ for about 1 hour in water bath. Then the solution was allowed to attend ambient temperature and the volume was made up to the mark with the mobile phase.

\section{Thermal degradation study}

$1 \mathrm{~mL}$ of stock solution was transferred into a $50 \mathrm{~mL}$ volumetric flask containing $20 \mathrm{~mL}$ of mobile phase. The volumetric flask was kept at $70^{\circ} \mathrm{C}$ for 4 hours in water bath. Then the solution was allowed to attend ambient temperature and the volume was made up to the mark with mobile phase.

\section{Photolytic degradation study}

$1 \mathrm{~mL}$ of stock solution was transferred into a $50 \mathrm{~mL}$ volumetric flask containing $20 \mathrm{~mL}$ of mobile phase. The solution was subjected to both of the cool white fluorescent and near ultraviolet lamp with a maximum energy emission at $365 \mathrm{~nm}$ for 4 
hours. Then the solution was allowed to attend ambient temperature and the volume was made up to the mark with mobile phase.

All treated solutions were filtered with a $0.45 \mu \mathrm{m}$ nylon syringe filter and injected in stabilized chromatographic conditions.

\section{Application of the developed method}

Analysis of Benzalkonium chloride in ophthalmic solutions

The developed method was applied to determine BAC content in the following ophthalmic preparations: Latanoprost; Latanoprost \& Timolol maleate; Brimonidine tartrate; Brimonidine tartrate \& Timolol maleate; Dexamethasone sodium phosphate, Chloramphenicol \& Tetrahydrozoline hydrochloride; Ketorolac tromethamine; Olopatadine hydrochloride; Dorzolamide hydrochloride \& Timolol maleate; Pheniramine maleate \& Naphazoline hydrochloride; and Tetrahydrozoline hydrochloride.

$5 \mathrm{~mL}$ of each of these solutions was diluted to $10 \mathrm{~mL}$ with mobile phase, filtered using a $0.45 \mu \mathrm{m}$ nylon syringe filter, and injected in stabilized chromatographic conditions.

Benzalkonium chloride percentage was calculated in comparison with a standard solution having a corresponding concentration using the following formula:

$$
\mathrm{BAC} \%=\left(r_{U} / r_{S}\right) \times\left(C_{S} / C_{U}\right) \times P
$$

In which:

$r_{U}$ and $r_{S}$ are sum of the peak areas for all BAC homologs obtained from the sample solution and the standard solution, respectively.

$C_{S}$ is the concentration, in $\mu \mathrm{g}$ per $\mathrm{mL}$, of BAC in the standard solution.

$C_{U}$ is the nominal concentration, in $\mu \mathrm{g}$ per $\mathrm{mL}$, of $\mathrm{BAC}$ in the sample solution.

$P$ is the potency of standard (as percentage).

\section{In-use stability study}

In-use stability study was applied for Latanoprost \& Timolol maleate, and Dorzolamide hydrochloride \& Timolol maleate ophthalmic solutions. The study was performed at $30^{\circ} \mathrm{C} \pm$ $2{ }^{\circ} \mathrm{C} / 65 \% \mathrm{RH} \pm 5 \% \mathrm{RH}$.

Products, at the end of their shelf-life, were treated in a manner simulates the use in practice. At the end of proposed in-use period, the remaining amounts of samples were tested.

Part of the applied tests was determining the change in BAC content during in-use shelf-life; therefore BAC was assayed at the initial $\left(\mathrm{T}_{0}\right)$ and after 30 days of opening $\left(\mathrm{T}_{30}\right)$, using the developed HPLC method.

This stability study included also evaluating of BAC antimicrobial effectiveness, which carried out as prescribed in US Pharmacopoeia (USP, 2012).

\section{RESULTS AND DISCUSSION}

\section{Method validation}

Suitability test was performed to ascertain the effectiveness of the operating chromatographic system, by evaluating specified parameters from five replicate injections of standard solution (100 $\mu \mathrm{g} / \mathrm{mL}$ of BAC in mobile phase). The results for each of $\mathrm{BAC}$ homologs were within the acceptable limits as per FDA guideline (FDA, 1994), as shown in Table 1.

Table 1: System suitability test results.

\begin{tabular}{|c|c|c|c|c|c|}
\hline Parameter & 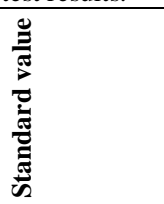 & 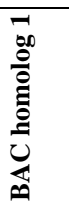 & 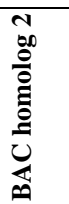 & 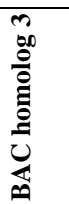 & 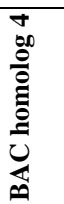 \\
\hline RSD\% of area & $\leq 1 \%$ for $n=5$ & 0.13 & 0.39 & 0.95 & 0.38 \\
\hline $\begin{array}{c}\text { RSD\% of } \\
\text { retention time }\end{array}$ & $\leq 1 \%$ for $n=5$ & 0.35 & 0.36 & 0.41 & 0.44 \\
\hline Tailing factor $(\mathbf{T})$ & $\leq 2$ & 1.36 & 1.24 & 1.19 & 1.22 \\
\hline Capacity factor ( $\left.k^{\prime}\right)$ & $>2$ & 2.60 & - & - & - \\
\hline Resolution (R) & $>2$ & - & 2.26 & 2.33 & 2.39 \\
\hline Theoretical plates $(\mathbf{N})$ & $>2000$ & 6587 & 7421 & 7875 & 7791 \\
\hline
\end{tabular}

Specificity of the method was assessed by comparing the chromatograms obtained from reference standards [Fig. 2 - 3], Benzalkonium chloride 50\% solution [Fig. 4], and placebo solutions [Fig. 5] that were synthetic solutions consisted of all components of the studied ophthalmic preparations other than Benzalkonium chloride. The comparison showed no interfering peaks at the retention times of BAC homologs in the placebo chromatograms that indicates the specificity of the method. Specificity was further studied by conducting the force degradation studies.

The method was linear over the range of $12.5 \mu \mathrm{g} / \mathrm{mL}$ to $400 \mu \mathrm{g} / \mathrm{mL}$, as the calibration curve - plotted over 6 different concentrations - had a correlation coefficient $\left(\mathrm{R}^{2}\right)$ value of 0.999937. The calibration curve is shown in [Fig. 6].

The method precision was assessed through repeatability (intra-day) and intermediate precision. Six determinations at concentration of $100 \mu \mathrm{g} / \mathrm{mL}$ were performed on the same day and under the same conditions for repeatability (intra-day). The intermediate precision was carried out at three concentration levels $(25,100$, and $200 \mu \mathrm{g} / \mathrm{mL})$, three replicates for each level by three different analysts. RSD\% values less than $2 \%$ indicate the precision of the method. Recovery tests were done to assess the accuracy of the described method, which carried out by the spiked - placebo recovery method at three concentration levels $(25,100$, and $200 \mu \mathrm{g} / \mathrm{mL}$ ), in three replicates for each level. The recoveries obtained confirmed that the proposed method was accurate. The results of accuracy and precision studies of the proposed method are tabulated in Table 2 .

The robustness of the method was evaluated to assure its reliability during normal usage, by making small changes in some method parameters including mobile phase $\mathrm{pH}( \pm 0.1)$, flow rate $( \pm$ $0.1 \mathrm{~mL} /$ minute), and wavelength $( \pm 3 \mathrm{~nm})$, in addition to use another column from different supplier (Thermo CPS Hypersil column); System suitability parameters were measured from five replicate injections of standard solution under each condition, and found to be within the acceptable limits indicating that method was robust. 


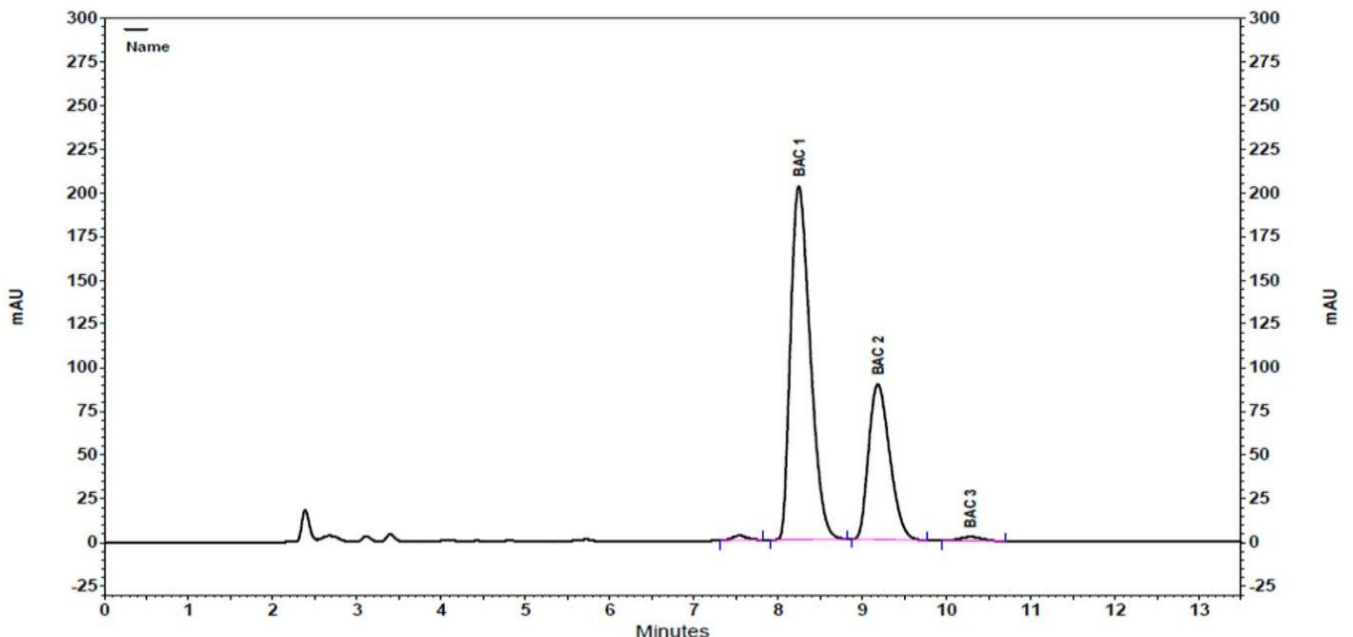

Fig. 2: Representative chromatogram of Benzalkonium chloride European Pharmacopoeia reference standard $(80 \mu \mathrm{g} / \mathrm{mL}$ of BAC).

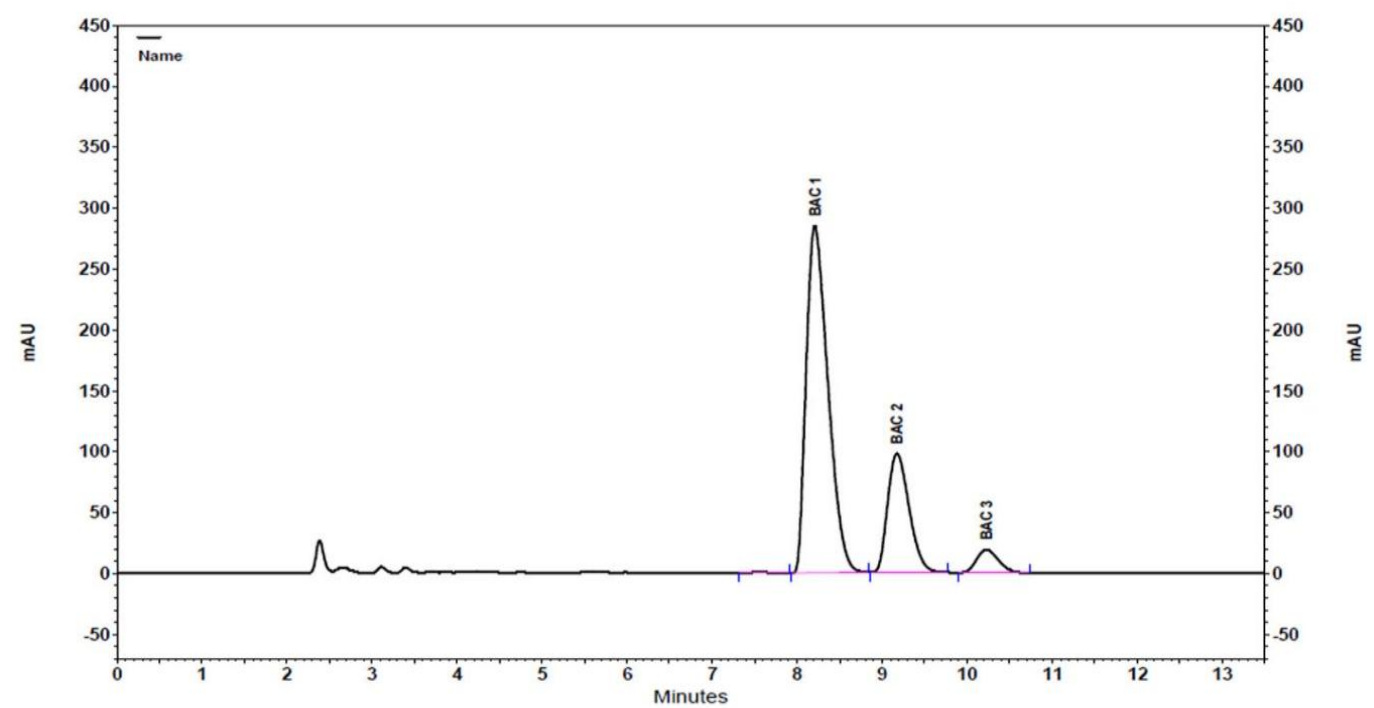

Fig. 3: Representative chromatogram of Benzalkonium chloride U.S. Pharmacopoeia reference standard ( $100 \mu \mathrm{g} / \mathrm{mL}$ of BAC).

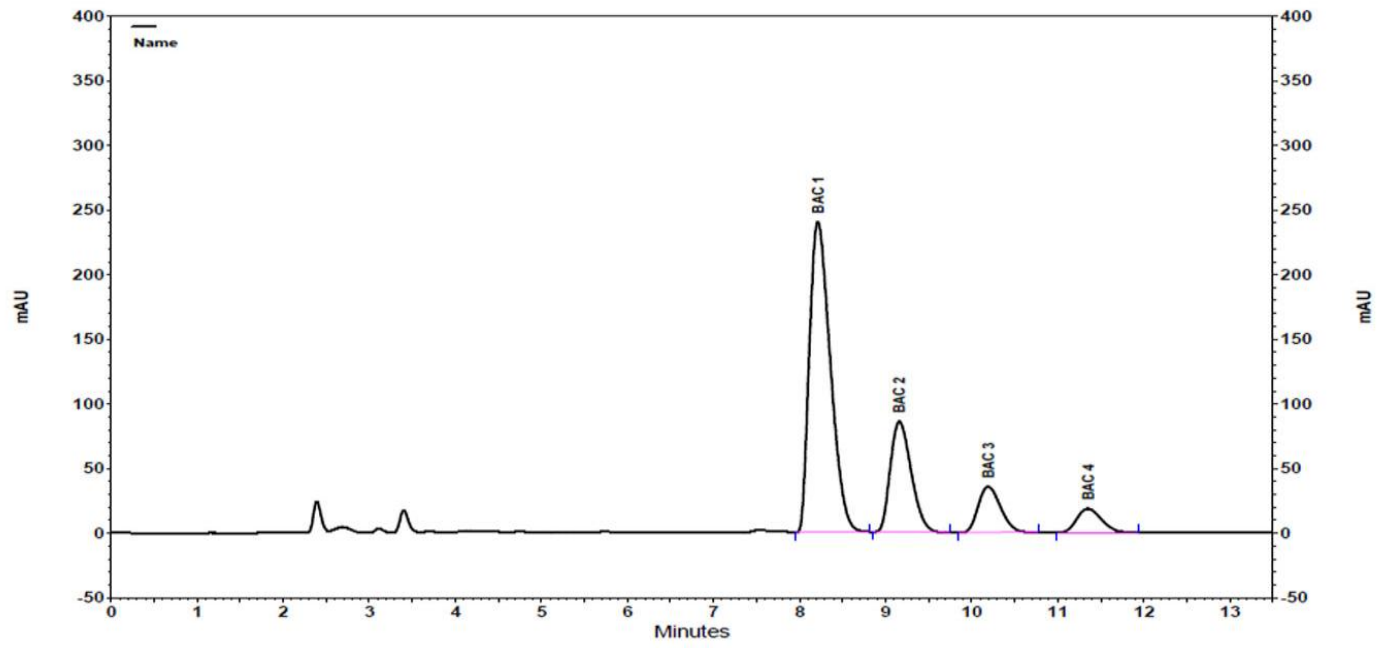

Fig. 4: Representative chromatogram of Benzalkonium chloride $50 \%$ solution (100 $\mu \mathrm{g} / \mathrm{mL}$ of BAC). 

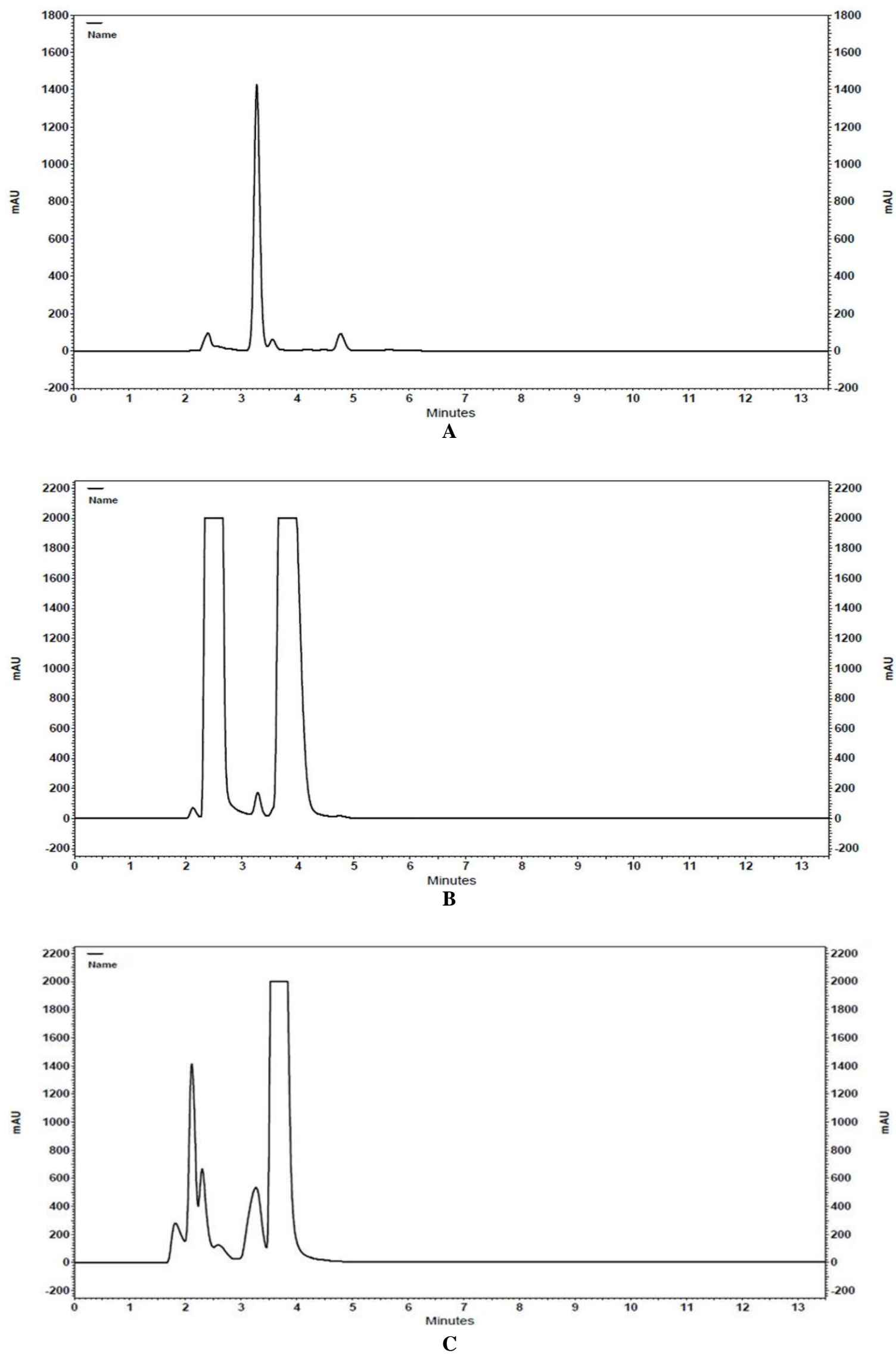

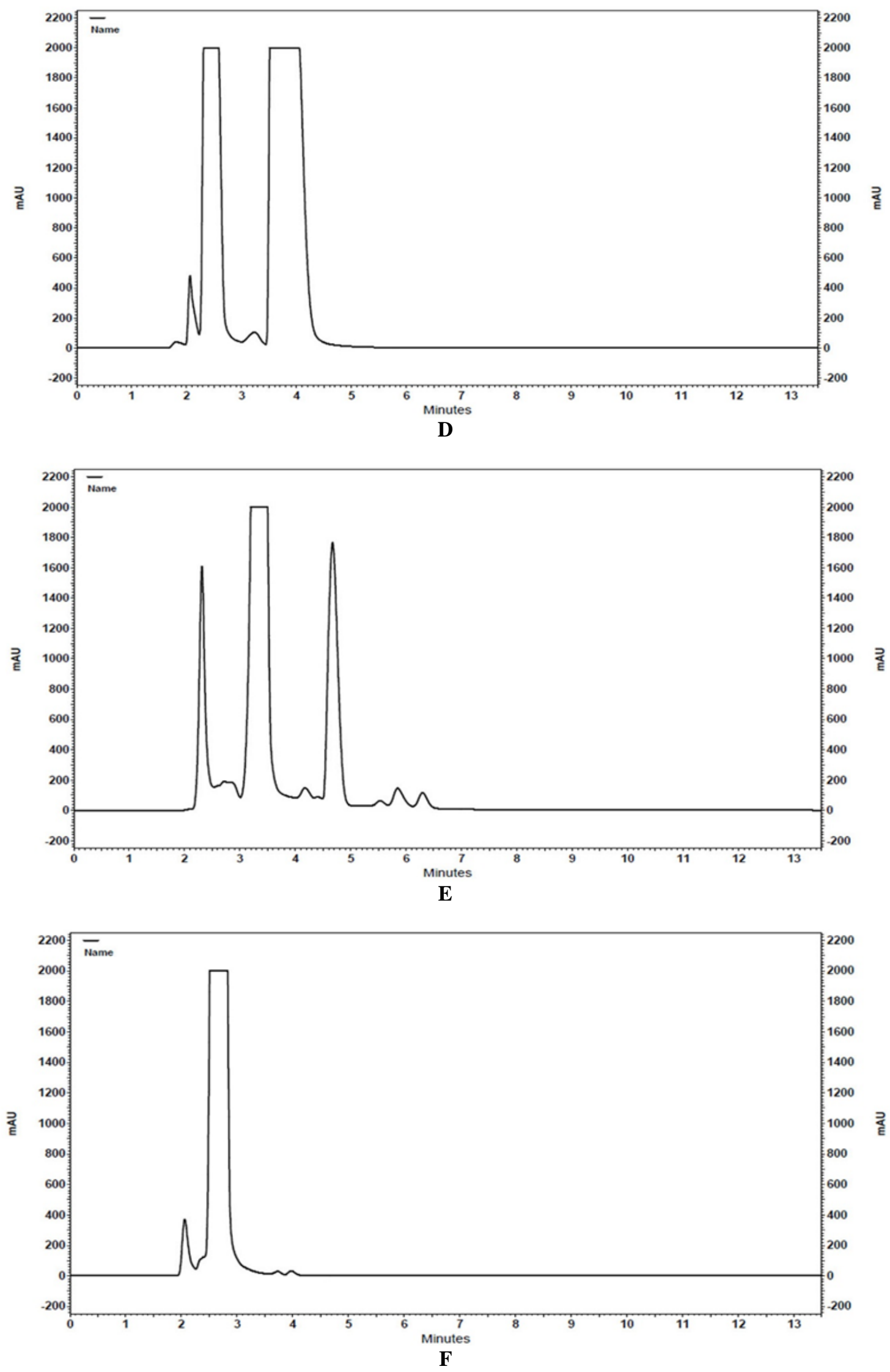

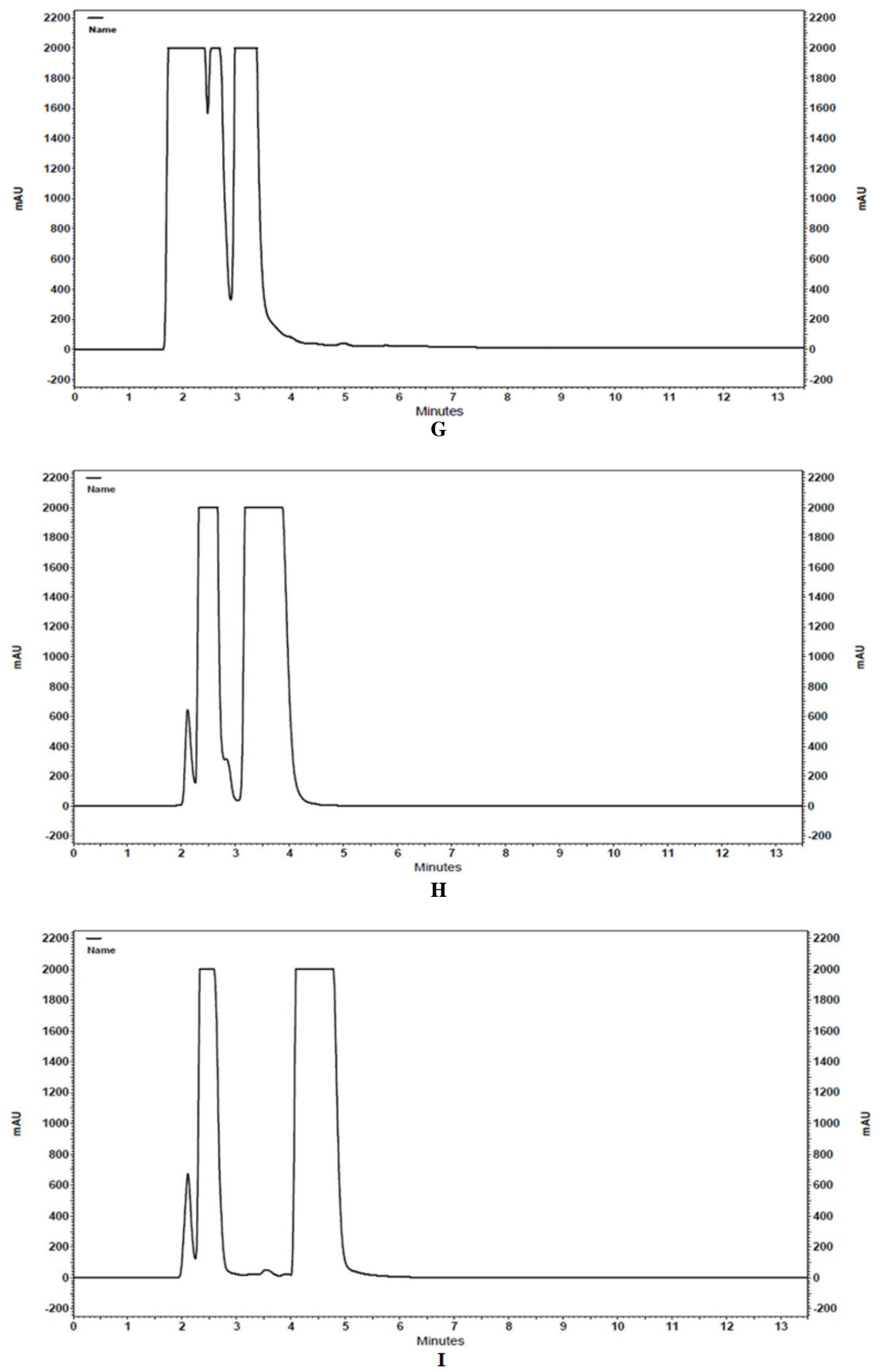


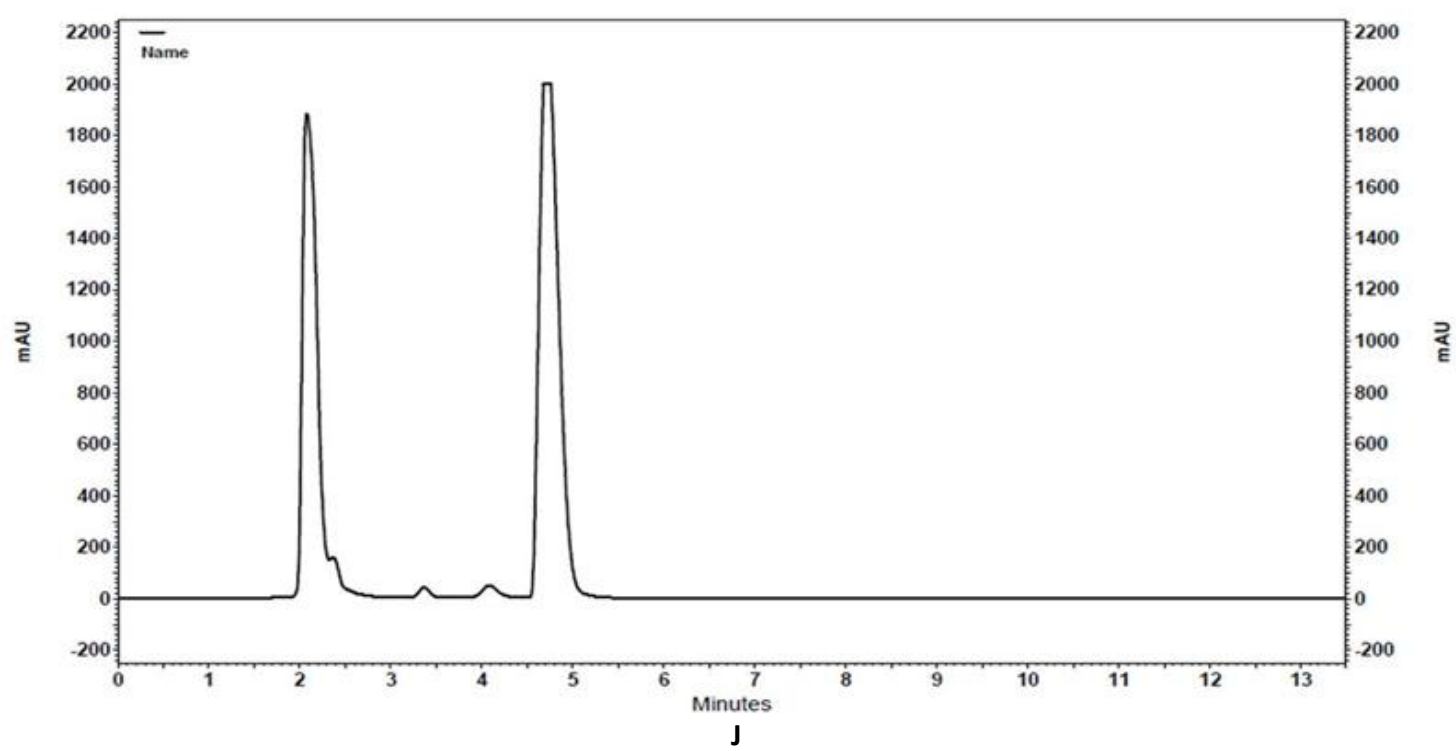

Fig. 5: Representative chromatograms of placebo solutions of the following ophthalmic solutions:

(A) Latanoprost; (B) Latanoprost \& Timolol maleate; (C) Brimonidine tartrate; (D) Brimonidine tartrate \& Timolol maleate; (E) Dexamethasone sodium phosphate, Chloramphenicol \& Tetrahydrozoline hydrochloride; (F) Ketorolac tromethamine; (G) Olopatadine hydrochloride; (H) Dorzolamide hydrochloride \& Timolol maleate; (I) Pheniramine maleate \& Naphazoline hydrochloride; and (J) Tetrahydrozoline hydrochloride

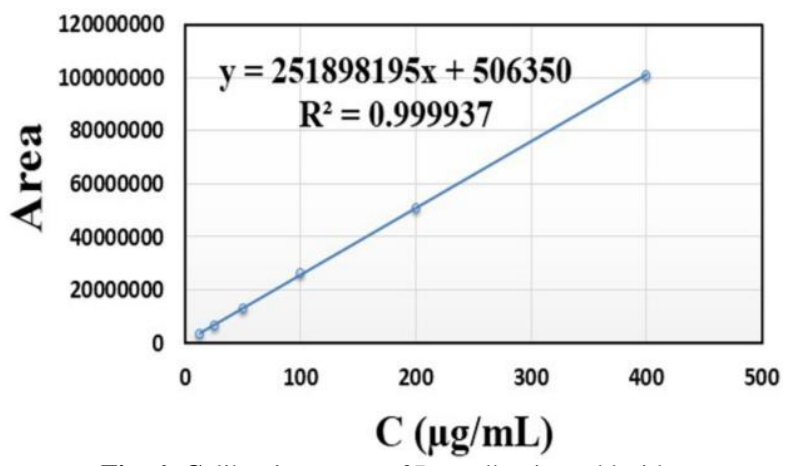

Fig. 6: Calibration curve of Benzalkonium chloride.

Table 2: Results of accuracy and precision studies.

\begin{tabular}{|c|c|c|c|c|c|c|}
\hline \multirow{2}{*}{\multicolumn{3}{|c|}{ Accuracy (Recovery \%) }} & \multicolumn{4}{|c|}{ Precision (RSD\%) } \\
\hline & & & Repeatability (Intra-day) & & ediate preci & \\
\hline $25 \mu \mathrm{g} / \mathrm{mL}$ & $100 \mu \mathrm{g} / \mathrm{mL}$ & $200 \mu \mathrm{g} / \mathrm{mL}$ & $100 \mu \mathrm{g} / \mathrm{mL}$ & $25 \mu \mathrm{g} / \mathrm{mL}$ & $100 \mu \mathrm{g} / \mathrm{mL}$ & $200 \mu \mathrm{g} / \mathrm{mL}$ \\
\hline $101.41 \% \pm 0.41 \%$ & $101.73 \% \pm 0.71 \%$ & $100.40 \% \pm 0.49 \%$ & $0.48 \%$ & $0.72 \%$ & $0.85 \%$ & $0.40 \%$ \\
\hline
\end{tabular}

\section{Carryover study}

Carryover was evaluated by injecting mobile phase after solution with high concentration of BAC $(400 \mu \mathrm{g} / \mathrm{mL})$. Carryover was expressed as total $\mathrm{BAC}$ peaks area ratio of the mobile phase against that form BAC solution. Carryover percentage was found to be $0.48 \%$, which is within the acceptance limit $(\leq 1 \%)$ (Kassaye and Genete, 2013).

\section{Filter validation}

Adsorption of the BAC onto the $0.45 \mu \mathrm{m}$ nylon syringe filter, used to prepare solutions for injection in the chromatographic system, was evaluated by analyzing unfiltered and filtered artificially prepared sample solutions, then comparing the results. Recovery percentage of BAC (filtered to unfiltered) was $100.59 \% \pm 0.35 \%$.

\section{Forced degradation studies}

After conducting the degradation conditions, BAC content was determined in the treated solutions. The results are presented in Table3. In the resulted chromatograms, no interference was observed between BAC homologs and the degradation products. The peak purity spectrum of BAC homologs was recorded using UV photo diode array detector. Peak purity results were greater than 0.99 indicating that the peaks were homogeneous in all stress conditions tested, which confirm the specificity and the stability-indicating property of the developed method. 
Table 3: Results of forced degradation studies.

\begin{tabular}{lr}
\hline Stress condition & BAC Assay \% \\
\hline Acidic degradation & $98.06 \% \pm 0.45 \%$ \\
Alkaline degradation & $94.62 \% \pm 0.86 \%$ \\
Oxidative degradation & $98.76 \% \pm 0.54 \%$ \\
Thermal degradation & $99.21 \% \pm 0.52 \%$ \\
Photolytic degradation & $99.28 \% \pm 0.62 \%$ \\
\hline
\end{tabular}

Table 4: Results of Benzalkonium chloride content in ophthalmic solutions.

\begin{tabular}{|c|c|c|}
\hline Ophthalmic solution & Labeled Content (mg/mL) & BAC content \% \\
\hline Latanoprost & 0.2 & $104.09 \% \pm 0.29 \%$ \\
\hline Latanoprost \& Timolol maleate & 0.2 & $103.14 \% \pm 0.72 \%$ \\
\hline Brimonidine tartrate & 0.05 & $104.88 \% \pm 0.31 \%$ \\
\hline Brimonidine tartrate \& Timolol maleate & 0.05 & $101.94 \% \pm 0.68 \%$ \\
\hline Dexamethasone sodium phosphate, Chloramphenicol \& Tetrahydrozoline hydrochloride & 0.1 & $100.83 \% \pm 0.47 \%$ \\
\hline Ketorolac tromethamine & 0.1 & $105.00 \% \pm 0.26 \%$ \\
\hline Olopatadine hydrochloride & 0.1 & $98.45 \% \pm 0.22 \%$ \\
\hline Dorzolamide hydrochloride \& Timolol maleate & 0.07 & $102.98 \% \pm 0.34 \%$ \\
\hline Pheniramine maleate \& Naphazoline hydrochloride & 0.1 & $101.28 \% \pm 0.39 \%$ \\
\hline Tetrahydrozoline hydrochloride & 0.1 & $98.36 \% \pm 0.83 \%$ \\
\hline
\end{tabular}

Table 5: Results of Benzalkonium chloride assay during in-use stability study.

\begin{tabular}{lrr}
\multicolumn{1}{c}{ Ophthalmic solution } & \multicolumn{2}{c}{ BAC content \% } \\
\cline { 2 - 3 } & $\mathbf{T}_{\mathbf{0}}$ & $\mathbf{T}_{\mathbf{3 0}}$ \\
\hline Latanoprost \& Timolol maleate & $103.65 \% \pm 0.40 \%$ & $103.81 \% \pm 0.63 \%$ \\
Dorzolamide hydrochloride \& Timolol maleate & $102.46 \% \pm 0.54 \%$ & $101.98 \% \pm 0.50 \%$ \\
\hline
\end{tabular}

Table 6: Results of antimicrobial effectiveness test during in-use stability study.

\begin{tabular}{|c|c|c|c|c|c|c|}
\hline & \multicolumn{2}{|c|}{ Acceptance criteria } & \multicolumn{2}{|c|}{ Latanoprost \& Timolol maleate solution } & \multicolumn{2}{|c|}{$\begin{array}{c}\text { Dorzolamide hydrochloride \& Timolol } \\
\text { maleate solution }\end{array}$} \\
\hline & Bacteria & Yeast and Molds & Bacteria & Yeast and Molds & Bacteria & Yeast and Molds \\
\hline $7^{\text {th }}$ day & NLT 1.0 log reduction & No increase & 1.0 log reduction & No increase & $1.0 \log$ reduction & No increase \\
\hline $14^{\text {th }}$ day & NLT $3.0 \mathrm{log}$ reduction & No increase & $3.9 \log$ reduction & No increase & $3.8 \log$ reduction & No increase \\
\hline $28^{\text {th }}$ day & No increase & No increase & No increase & No increase & No increase & No increase \\
\hline
\end{tabular}

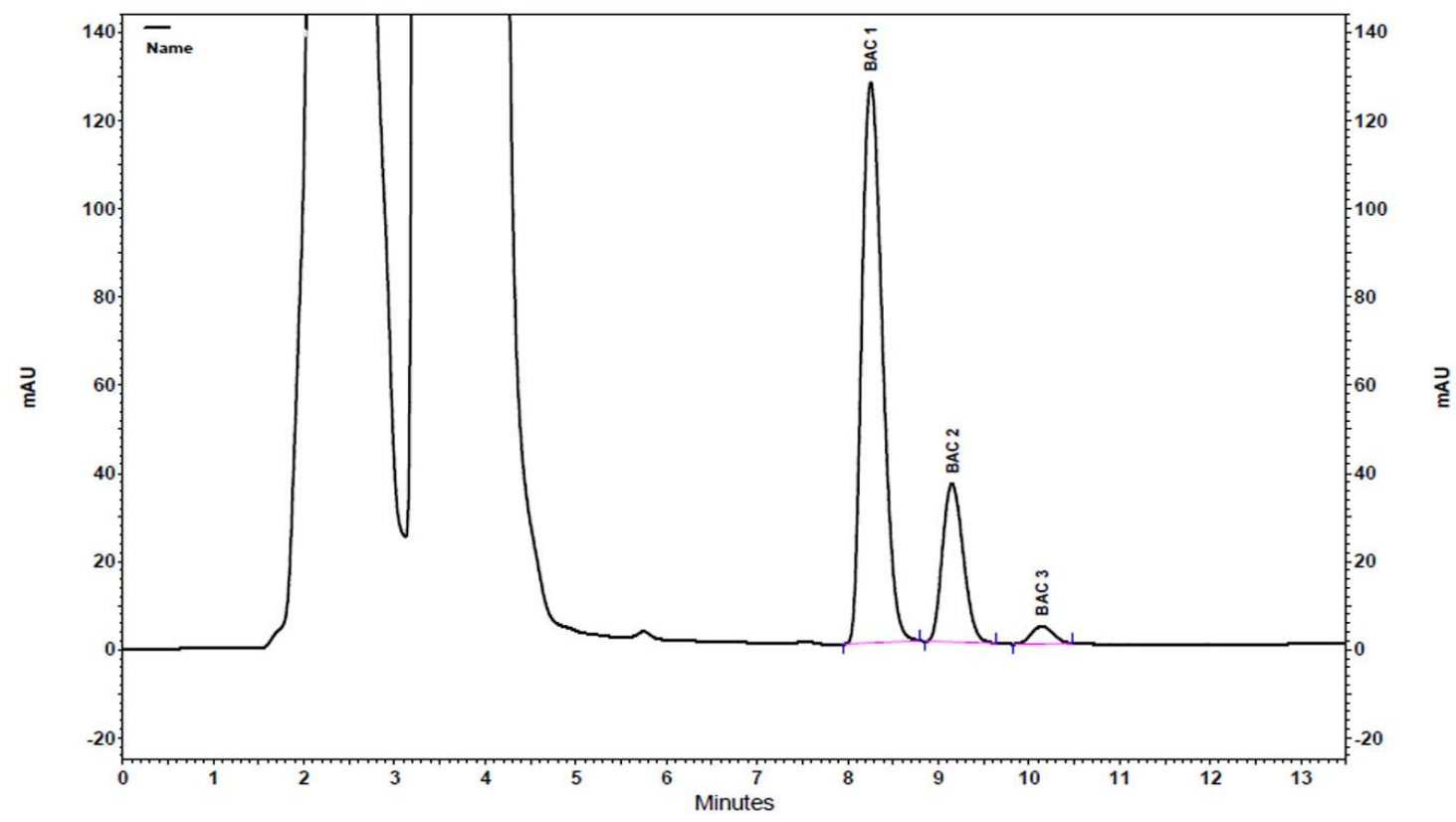

Fig. 7: Representative chromatogram of Dorzolamide hydrochloride \& Timolol maleate ophthalmic solution $(35 \mu \mathrm{g} / \mathrm{mL}$ of BAC) 
Application of the developed method Analysis of Benzalkonium chloride in ophthalmic solutions

The Benzalkonium chloride content in the tested preparations is presented in Table 4. The chromatogram resulted from analysis of Dorzolamide hydrochloride \& Timolol maleate ophthalmic solution is represented in [Fig. 7], as an example.

\section{In-use stability study}

As per the results in Table 5 and 6, there was no significant change in BAC content during in-use period, and both of studied ophthalmic solutions passed the test for antimicrobial effectiveness according to US Pharmacopoeia (USP, 2012).

\section{CONCLUSION}

This study presents a simple validated HPLC method for estimation of BAC in a variety of ophthalmic preparations. The developed method is specific, rapid, robust, precise and accurate. The results of forced degradation studies imply that the developed method is stability-indicating. Developed method can be used as quality control tool for routine quantitative analysis of $\mathrm{BAC}$ and stability studies.

\section{ACKNOWLEDGEMENTS}

The authors thank the quality control team in DIAMOND PHARMA for pharmaceutical industries, Syria, especially Ms. Sahar Muhaisen for the support.

\section{REFERENCES}

Agarwal A, Tiwari S, Nagariya K. Method Development and Its Validation for Quantitative Simultaneous Determination of Latanoprost, Timolol and Benzalkonium Chloride in Ophthalmic Solution by RPHPLC. Journal of Drug Delivery and Therapeutics, 2013; 3(2): 26-30.

Al-Fakhory AA, Al-Kalak I, Al-Khatib MJ. Chromatographic Determination of Total Benzalkonium Chloride [BAC] in Some of Ophthalmic Preparations by HPLC. Damascus University Journal for Basic and Applied Sciences, 2014; 30 (2): 155-171.

British Pharmacopoeia 2013. Efficacy of Antimicrobial Preservation (Appendix XVI C). London: Stationery Office.

Chiapetta SC, de Oliveira ÉC, Olivier BC, Mercante LA, Henriques DM, Pereira Netto AD. Intralaboratory Validation, Comparison and Application of HPLC-UV-DAD Methods for Simultaneous Determination of Benzalkonium Chloride, Chlorexidine Digluconate and Triclosan. J. Braz. Chem. Soc, 2011; 22(10): 1913-1920.

Dudkiewicz-Wilczyńska J, Tautt J, Roman I. Application of the HPLC Method for Benzalkonium Chloride Determination in Aerosol Preparations. Journal of pharmaceutical and biomedical analysis, 2004; 34(5): 909-920.

Food and Drug Administration. 1994. Reviewer Guidance Validation of Chromatographic Methods.

Freeman PD, Kahook MY. Preservatives in Topical Ophthalmic Medications: Historical and Clinical Perspectives. Expert Rev Ophthalmol, 2009; 4(1): 59-64

Gaber M, Shawish HMA, Khedr AM, Abed-Almonem KI. Determination of Benzalkonium Chloride Preservative in Pharmaceutical Formulation of Eye and Ear Drops Using New Potentiometric Sensors. Materials Science and Engineering: C, 2012; 32(8): 2299-2305.

ICH Harmonized Tripartite Guideline. 2005. Validation of Analytical Procedures: Text and Methodology. Q2 (R1).
Jovović M, Kostić N, Jančić-Stojanović B, Malenović A. Investigation of Tropicamide and Benzalkonium Chloride Stability Using Liquid Chromatography. Journal of Liquid Chromatography \& Related Technologies, 2012; 35(2): 231-239.

Kapakayala SV, Mubeen G, Kimbahune R. Reverse Phase-High Performance Liquid Chromatographic Method for Quantitation of Epinastine Hydrochloride in Eye Drops. Indo American Journal of Pharm Research, 2013; 3(9): 7541-7548.

Kassaye L, Genete G. Performance Verification Test of High Performance Liquid Chromatography: Practical Example. International Journal of Chromatographic Science, 2013; 3(1): 18-23.

Kostić DA, Mitić SS, Nasković DČ, Zarubica AR, Mitic MN. Determination of Benzalkonium Chloride in Nasal Drops by HighPerformance Liquid Chromatography. Journal of Chemistry, 2012; 9(3): 1599-1604.

Liu J, Lu GW, Sandoval M, Ciringh Y, Xue G, Jaeger D, Kompanik K, Jiao J, Gelotte KM. Determination of Benzalkonium Chloride Partition in Micelle Solutions Using Ultrafiltration Method. AAPS PharmSciTech, 2009; 10(4): 1216-1223.

Mehta J, Patidar K, Vyas N. Development and Validation of a Precise Method for Determination of Benzalkonium Chloride (BKC) Preservative, in Pharmaceutical Formulation of Latanoprost Eye Drops. Journal of Chemistry, 2010; 7(1): 11-20.

Rao PV, Venkatesh P, Kumar MR. Validated Stability Indicating UPLC Method for the Estimation of Benzalkonium Chloride in Ketorolac Tromethamine Ophthalmic Solution. International Journal of Chromatographic Science, 2013; 3(1): 5-9.

Santos M, Li M, Rustum AM. A Single RP-LC Method for the Determination of Benzalkonium Chloride and Its Potential Impurities in Benzalkonium Chloride Raw Material. Chromatographia, 2010; 71(5-6): 499-503.

Semwal UP, Sharma P, Sharma A, Singh GN. Evaluation of Preservative Effectiveness in Ophthalmic Drops by Microbial Challenge Test. World J Pharm Sci, 2015; 3(1): 31-36.

Shaikh KA, Patil AT. Stability-Indicating HPLC Method for the Determination of Mometasone Furoate, Oxymetazoline, Phenyl Ethanol and Benzalkonium Chloride in Nasal Spray Solution. Journal of Trace Analysis in Food and Drugs, 2013; 1: 14-21.

Shen $\mathrm{Y}, \mathrm{Xu} \mathrm{SJ}$, Wang SC, Tu JS. Determination of Benzalkonium Chloride in Viscous Ophthalmic Drops of Azithromycin by High-Performance Liquid Chromatography. J Zhejiang Univ Sci B, 2009; 10(12): 877-882.

Trivedi HK, Patel C. Development and Validation of a Precise and Stability Indicating LC Method for the Determination of Benzalkonium Chloride in Pharmaceutical Formulation Using an Experimental Design. Journal of Chemistry, 2010; 7(4): 1514-1522.

Trivedi RK, Challa S, Patel MC, Trivedi DR, Chatrabhuji PM. A Rapid, Stability-Indicating RP-UPLC Method for the Simultaneous Determination of Fluticasone Furoate and Benzalkonium Chloride in a Pulmonary Drug Product. Chem Sci Trans., 2013; 2(4): 1184-1191.

United States Pharmacopeia, USP35-NF30. 2012.

Antimicrobial Effectiveness Testing (51): 52

United States Pharmacopeia, USP35-NF30. 2012 Benzalkonium Chloride: 1708.

World Health Organization. 2009. Stability Testing of Active Pharmaceutical Ingredients and Finished Pharmaceutical Products (Annex 2). WHO Technical Report Series, Geneva, No. 953.

\section{How to cite this article:}

AlAani H, AlNukkary Y. Determination of Benzalkonium Chloride in Ophthalmic Solutions by Stability-Indicating HPLC Method: Application to a Stability Study. J App Pharm Sci, 2016; 6 (05): 080-089. 